Pacific Journal of Mathematic 


\section{REMARK ON THE AVERAGES OF REAL FUNCTIONS}

\section{R. E. Chamberlin}

1. Introduction. Let $f(x)$ be a continuous function defined on the closed interval $[a, b]$. It is known that if for each $x$ in the open interval $(a, b)$ there is a positive number $t$ such that

$$
[x-t, x+t] \subset(a, b) \text { and } f(x)=\frac{f(x-t)+f(x+t)}{2}
$$

then $f(x)$ is linear (see [2, p. 253]). The same method of proof shows that if there is such a $t$ for each $x \in(a, b)$ with

$$
f(x)=\frac{1}{2 t} \int_{x-t}^{x+t} f(s) d s
$$

then $f(x)$ is linear. Suppose $f(x)$ is such that for each $x \in(a, b)$ there exists a $t$ with $[x-t, x+t] \subset(a, b)$ and

$$
\frac{f(x+t)+f(x-t)}{2}=\frac{1}{2 t} \int_{x-t}^{x+t} f(s) d s .
$$

Is $f(x)$ necessarily linear? On page 231 of [1] it is shown that if (1) holds for each $x$ and all $t$ such that $[x-t, x+t] \subset(a, b)$ then $f(x)$ is linear. The question arises whether or not one can relax the requirement that (1) holds for all $t$ in the above intervals and still conclude that $f(x)$ is linear.

In this note a continuously differentiable non-linear function $f(x)$ is given which satisfies (1) for every $x \in(a, b)$ and an infinity of $t$ 's. The values of $t$ depend on $x$ but they may be chosen arbitrarily small for each $x$. Conditions which together with (1) make $f(x)$ linear are given and the note is concluded with some remarks on the approximation to a function by its averages

$$
f(x, t)=\frac{1}{2 t} \int_{x-t}^{x+t} f(s) d s .
$$

DEFINITION. A continuous function $f(x)$ on $[a, b]$ will be said to have property (1) if for each $x \in(a, b)$ there are arbitrarily small values of $t$ for which (1) is true.

2. An example. We give an example of a continuously differentiable function having property (1) which is not linear. Let

Received January 14, 1954. 


$$
f(x)=\sum_{n=1}^{\infty} \frac{\cos 10^{2 n} \pi x}{n^{2} \cdot 10^{2 n}}
$$

It is clear that $f(x)$ is not linear and is continuously differentiable. To show that $f(x)$ has property (1) we begin with the following

LemMA. For every $x$,

$$
\lim _{n \rightarrow \infty}\left|\cos 10^{2 n} \pi x\right| \geq 10^{-3} .
$$

Since the functions $\cos 10^{2 n} \pi x(n \geq 1)$ all have 1 as a period it is clear we need only consider $x \in[0,1]$ in the proof of this lemma. Since there is no loss in generality we assume hereafter that we are dealing with the interval $[0,1]$ and $x$ is in this interval.

Let the decimal expansion of $x$ be.$a_{1} a_{2} \cdots$. Then

$$
10^{2 n} x=a_{1} a_{2} \cdots a_{2 n}+. a_{2 n+1} a_{2 n+2} \cdots \text { and }\left|\cos 10^{2 n} \pi x\right|=\left|\cos \left(. a_{2 n+1} a_{2 n+2} \cdots\right) \pi\right| .
$$

Suppose $\left|\cos 10^{2 n} \pi x\right|<10^{-3}$. Set $. a_{2 n+1} a_{2 n+2} \cdots=.5+r_{n}$ where $\left|r_{n}\right|<.5$. Then

$$
10^{-3} \geq\left|\cos \left(. a_{2 n+1} a_{2 n+2} \cdots\right) \pi\right|=\left|\sin r_{n} \pi\right|=\sin \left|r_{n} \pi\right| \geq \frac{2}{\pi} r_{n} \pi \mid,
$$

that is $\frac{1}{2 \cdot 10^{3}} \geq\left|r_{n}\right|$. Hence there is an integer $b$ with $0 \leq b \leq 5$ such that $\left|r_{n}\right|=.000 b \cdots$. Therefore,

$$
\left|\cos 10^{2(n+1)} \pi x\right|=|\cos (.0 b \cdots) \pi| \geq\left(1-\frac{(.1 \pi)^{2}}{2}\right)>.9 .
$$

Thus for every $x$ and every $n_{0}$ there are integers $n>n_{0}$ such that $\left|\cos 10^{2 n} \pi x\right| \geq 10^{-3}$. This proves the lemma.

For the function (2) we have

$$
\begin{aligned}
& g(x, t)= \frac{1}{2}[f(x+t)+f(x-t)]-\frac{1}{2 t} \int_{x-t}^{x+t} f(s) d s \\
&= \sum_{n=1}^{\infty} \frac{1}{2 \cdot 10^{2 n} \cdot n^{2}}\left[\cos 10^{2 n} \pi(x+t)+\cos 10^{2 n} \pi(x-t)\right] \\
&-\frac{1}{2 t} \sum_{n=1}^{\infty} \sin 10^{2 n} \pi(x+t)-\sin 10^{2 n} \pi(-t) . \\
& 10^{2 n} \cdot n^{3} \cdot 10^{2 n} \pi
\end{aligned}
$$

From elementary trigonometric identities we now obtain

$$
g(x, t)=\sum_{n=1}^{\infty} \frac{1}{10^{2 n} n^{2}} \cos 10^{2 n} \pi x\left[\cos 10^{2 n} \pi t-\frac{\sin 10^{2 n} \pi t}{10^{2 n} \pi t}\right] .
$$


We investigate in detail the last expression for $g(x, t)$ in (3).

Given $x$, let $\varlimsup_{n \rightarrow \infty}\left|\cos 10^{2 n} \pi x\right|=d$. From the lemma it is clear there are an infinity of integers $k$ with the following properties:

(a) $\left|\cos 10^{2 k} \pi x\right|>.99 d$.

(b) $\left|\cos 10^{2 n} \pi x\right|<1.01 d$ for $n \geq[k / 3]$

(c) $k \geq 10$.

For these values of $k$ we show that the sign of $g(x, t)$ in $(3)$ is determined by the sign of the $k$-th term in its series expansion if $t$ is chosen properly. We assume hereafter that $k$ is subject to conditions (a), (b) and (c).

For the given $x$ and subject to conditions (a), (b) and (c) pick $k$ large enough so that for $t=2 \cdot 10^{-2 k},[x-t, x+t] \subset[0,1]$. Then

(4) $g\left(x, 10^{-2 k}\right)=\sum_{n=1}^{\infty} \frac{\cos 10^{2 n} \pi x}{n^{2} 10^{2 n}}\left[\cos 10^{2(n-k)} \pi-\frac{\sin 10^{2(n-k)} \pi}{10^{2(n-k)} \pi}\right]$

$=\sum_{n=1}^{k-1} \frac{\cos 10^{2 n} \pi x}{n^{2} 10^{2 n}}\left(-\pi_{6}^{2} 10^{4(n-h)}+\theta_{n} \cdot 10^{6(n-k)}\right)+(-1) \cdot \frac{\cos 10^{2 k} \pi x}{k^{2} 10^{2 k}}+\sum_{n=k+1}^{\infty} \frac{\cos 10^{2 n} \pi x}{n^{2} 10^{2 n}}$

where $\left|\theta_{n}\right|<2$. Now

$$
\begin{aligned}
& \left|\sum_{n=1}^{k-1} \frac{\cos 10^{2 n} \pi x}{n^{2} 10^{2 n}}\left(-\frac{\pi^{2}}{6} 10^{ \pm(n-k)}+\theta_{n} 10^{6(n-k)}\right)\right|
\end{aligned}
$$

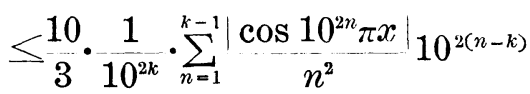

$$
\begin{aligned}
& \leq_{3}^{10} 10^{-2 k}\left(\sum_{n=1}^{[k / 3]-1} \frac{1}{n^{2}} 10^{2(n-k)}\right) \cdot 10^{3} d+\left(\frac{10}{3}\right) 10^{-2 k}\left(\sum_{n=[k / 3]}^{k-1} \frac{1}{n^{2}} 10^{2(n-k)}\right) 1.01 d
\end{aligned}
$$

where we have used the lemma and property (b) of $k$ to get the last inequality.

For the first sum in the last inequality of (5) we have

$$
\begin{aligned}
& \sum_{n=1}^{[k / 3]-1} \frac{1}{n^{2}} 10^{2(n-k)}<\sum_{n=1}^{[k / 3]-1} 10^{2(n-k)} \leq 10^{-4 / 3(k-1)} \frac{1-\left(10^{-2}\right)^{(k / 3)}}{1-10^{-2}} \\
& \quad<(1.01) 10^{-4 / 3(k-1)} .
\end{aligned}
$$

To get an estimate on the second part of the last inequality of (5), recall that if $s_{n}=\sum_{i=1}^{n} \alpha_{i}$ then

$$
\sum_{n=r}^{m} \alpha_{n} \beta_{n}=\sum_{n=r}^{m} s_{n}\left(\beta_{n}-\beta_{n+1}\right)-s_{r-1} \beta_{r}+s_{m} \beta_{m+1} .
$$


Letting $\alpha_{n}=10^{2(n-k)}, \beta_{n}=1 / n^{2}$ we get

$$
\begin{aligned}
& \sum_{n=[k / 3]}^{k-1} \frac{10^{2(n-k)}}{n^{2}}=\sum_{n=[k / 3]}^{k-1} 10^{-2(k-n)}\left(\frac{1-10^{-2 n}}{1-10^{-2}}\right)\left(\frac{1}{n^{2}}-\frac{1}{(n+1)^{2}}\right) \\
& -10^{-2(k-[k / 3]-1)}\left(\frac{1-10^{-2[k / 3]}}{1-10^{-2}}\right) \cdot 1 /[k / 3]^{2}+10^{-2}\left(\frac{1-10^{-2(k-1)}}{1-10^{-2}}\right) \cdot \frac{1}{k^{2}}<\frac{2}{10^{2}} \frac{1}{k^{2}}
\end{aligned}
$$

at least for $k \geq 10$. Using the estimates obtained in (6) and (7) we get

$$
\begin{aligned}
& \frac{10}{3} \cdot 10^{-2 k} \sum_{n=1}^{k-1} \frac{\left|\cos 10^{2 n} \pi x\right|}{n^{2} 10^{2 n}} \leq \frac{d}{10^{2 k}}\left[\frac{1.01}{3} 10^{-4 / 3(k-1)+4}+\frac{10}{3} \cdot(1.01) \cdot \frac{2}{10^{2} k^{2}}\right] \\
& \quad<\frac{2}{10} d \cdot \frac{1}{k^{2} 10^{2 k}} \text { for } k \geq 10 .
\end{aligned}
$$

Furthermore

$$
\begin{aligned}
& \mid \sum_{n=k+1}^{\infty} \frac{\cos 10^{2 n} \pi x}{10^{2 n} n^{2}}\left[\cos 10^{2(n-k)} \pi-\frac{\sin 10^{2(n-k)} \pi}{10^{2(n-k)} \pi}\right] \\
& \leq 1.01 d \sum_{n=k+1}^{\infty} \frac{1}{10^{2 n} n^{2}}<\frac{1.01 d}{(k+1)^{2}} \cdot \frac{1}{10^{2(k+1)}} \cdot \frac{1}{1-10^{-2}}<\frac{1}{10} \frac{d}{k^{2} 10^{2 k}} .
\end{aligned}
$$

From (8) and (9) we see that the $k$-th term of the series for $g\left(x, 10^{-2 k}\right)$ is greater in absolute value than the sum of the remaining terms. Hence the signs of $g\left(x, 10^{-2 k}\right)$ and $-10^{-2 k} k^{-2} \cos 10^{2 k} \pi x$ are the same. For $t=2 \cdot 10^{-2 k}$ the $k$-th term of the series for $g\left(x, 2 \cdot 10^{-2 k}\right)$ is $10^{-2 k} k^{-2} \cos 10^{2 k} \pi x$ and in the same manner as above one can show that the signs of $g\left(x, 2 \cdot 10^{-2 k}\right)$ and the $k$-th term are the same. Since $10^{-2 k} k^{-2} \cos 10^{2 k} \pi x$ and $-10^{-2 k} k^{-2} \cos 10^{2 k} \pi x$ are of opposite signs, $g(x, t)$ vanishes for some $t \in\left(10^{-2 k}, 2 \cdot 10^{-2 k}\right)$. But for $g(x, t)$ to vanish means that $f(x)$ satisfies (1). Since for each $x$ there are an infinity of $k$ 's satisfying (a), (b) and (c), there are (for each $x$ ) arbitrarily small values of $t$ for which the $f(x)$ of (2) satisfies (1). Hence this $f(x)$ has the property (1).

\section{Sufficient conditions for a function to be linear.}

LEMMA 1. If $f(x)$ is continuously differentiable and $f^{\prime \prime}\left(x_{0}\right) \neq 0$, then $g\left(x_{0}, t\right)$ is of one sign for some open interval $\left(0, t_{0}\right)\left(t_{0}>0\right)$.

Under the stated conditions we may represent $f(x)$ by

$$
f(x)=f\left(x_{0}\right)+f^{\prime}\left(x_{0}\right)\left(x-x_{0}\right)+\frac{f^{\prime \prime}\left(x_{0}\right)}{2}\left(x-x_{0}\right)^{2}+o\left[\left(x-x_{0}\right)^{2}\right] .
$$

Using (10) and the definition of $g(x, t)$ gives 
(11)

$$
\begin{aligned}
g\left(x_{0}, t\right)= & \frac{f\left(x_{0}+t\right)+f\left(x_{0}-t\right)}{2}-\frac{1}{2 t} \int_{x_{0}-t}^{x_{0}+t} f(u) d u \\
= & \left\{f\left(x_{0}\right)+\frac{f^{\prime \prime}\left(x_{0}\right)}{2} t^{2}+o\left(t^{2}\right)\right\}-\frac{1}{2 t} \int_{x_{0}-t}^{x_{0}+t}\left\{f\left(x_{0}\right)+f^{\prime}\left(x_{0}\right)\left(u-x_{0}\right)\right. \\
& \left.+\frac{f^{\prime}\left(x_{0}\right)}{2}\left(u-x_{0}\right)^{2}+o\left[\left(u-x_{0}\right)^{2}\right]\right\} d u=\frac{1}{3} f^{\prime \prime}\left(x_{0}\right) t^{2}+o\left(t^{2}\right) .
\end{aligned}
$$

Thus if $f^{\prime \prime}\left(x_{0}\right) \rightleftharpoons 0$, it is clear $g\left(x_{0}, t\right)$ is one-signed for sufficiently small values of $t$.

THEOREM 1. If $f(x)$ has property (1) and $f^{\prime}(x)$ is absolutely continuous then $f(x)$ is linear.

For $f^{\prime \prime}(x)$ exists almost everywhere and by Lemma 1 it is zero everywhere it exists because $f(x)$ has property (1). Hence $f^{\prime}(x)$ is a constant and $f(x)$ is linear.

THEOREM 2. If $f^{\prime}(x)$ is continusus, monotone increasing and not constant in any sufficiently small symmetric interval about $x_{0}$ then $g\left(x_{0}, t\right)$ is one-signed in an interval $\left(0, t_{0}\right)$.

One has

$$
f\left(x_{0}+t\right)=f\left(x_{0}-t\right)+\int_{x_{0}-t}^{x_{0}+t} f^{\prime}(u) d u
$$

and for any $x \in\left(x_{0}-t, x_{0}+t\right)$ we get

$$
f(x) \leq f\left(x_{0}-t\right)+f^{\prime}(x)\left(x-x_{0}+t\right), f\left(x_{0}+t\right) \geq f(x)+f^{\prime}(x)\left(x_{0}+t-x\right)
$$

where at least one of the inequalities is strict by the hypothesis of Theorem 2. From (12) one obtains

$$
\frac{\left(x-x_{0}+t\right) f\left(x_{0}+t\right)+\left(x_{0}-x+t\right) f\left(x_{0}-t\right)}{2 t}>f(x) .
$$

It is obvious from (13) that $g\left(x_{0}, t\right)$ is positive. Clearly this result with the inequality reversed holds if $f^{\prime}(x)$ is monotone decreasing.

We do not know if property (1) and bounded variation of $f^{\prime}(x)$ imply linearity for $f(x)$. In view of the two preceding theorems it seems quite likely.

\section{Remarks on the approximation of a function by its averages.}

Suppose $f(x)$ is a continuous function defined on the interval $(a-\delta, b+\delta)(\delta>0)$. We make some remarks on the approximation to 
$f(x)$ by its averages

$$
f(x, t)=\frac{1}{2 t} \int_{x-t}^{x+t} f(u) d u \quad(0<t<\delta), x \in[p, b] .
$$

If $f(x)$ is linear then $f(x, t) \equiv f(x)$. If $f(x)$ is not linear in any subinterval then there is an everywhere dense subset of points $x$ at which the approximating functions are all either above or below $f(x)$. Otherwise the conditions of the theorem of [2, p. 253] are met and $f(x)$ would be linear.

One might ask if there are necessarily points at which $f(x, t)$ approaches $f(x)$ monotonely. From the results of $\S 2$ above this can be seen to be false. For $t>0, f(x, t)$ is continuously differentiable function of $t$ and

$$
f_{t}(x, t)=\frac{1}{t}\left\{\frac{f(x+t)+f(x-t)}{2}-\frac{1}{2 t} \int_{x-t}^{x+t} f(u) d u\right\}=\frac{1}{t} g(x, t) .
$$

From this it is clear the function of $\S 2$ gives an example of a continuously differentiable function which at no point is approximated monotonely by its averages.

\section{REFERENCES}

1. E.F. Beckenbach and M.O. Reade, "Mean values and harmonic polynomials", Trans. Amer. Math. Soc., 53 (1943), 230-238.

2. R. Courant and D. Hilbert, "Methoden der mathematischen Physik.", 2, Berlin, 1937.

UNIVERSITY OF UTAH 


\section{PACIFIC JOURNAL OF MATHEMATICS}

\section{EDITORS}

\author{
H. L. Royden \\ Stanford University \\ Stanford, California \\ E. Hewite \\ University of Washington \\ Seattle 5 , Washington
}

\author{
R. P. Dilworth
}

California Institute of Technology Pasadena 4, California

\section{A. HorN*}

University of California

Los Angeles 24, California

\section{ASSOCIATE EDITORS}

\author{
H. BUSEMANN \\ HERBERT FEDERER \\ MARSHALL HALL
}

\author{
P. R. HALMOS \\ HEINZ HOPF \\ ALFRED HORN
}

\author{
R. D. JAMES \\ BORGE JESSEN \\ PAUL LÉVY
}

GEORGE PÓLYA

J. J. STOKER

KOSAKU YOSIDA

\section{SPONSORS}

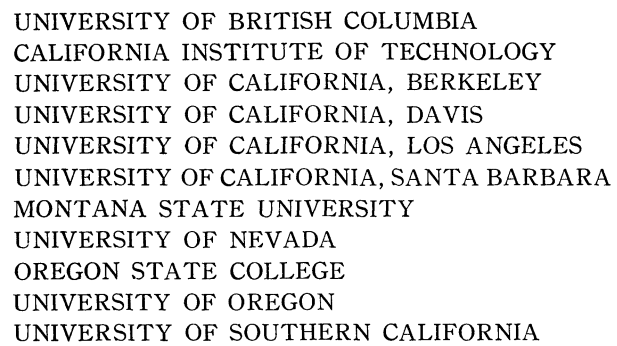

UNIVERSITY OF BRITISH COLUMBIA

CALIFORNIA INSTITUTE OF TECHNOLOGY

UNIVERSITY OF CALIFORNIA, BERKELEY

UNIVERSITY OF CALIFORNIA, DAVIS

UNIVERSITY OF CALIFORNIA, LOS ANGELES

UNIVERSITY OF CALIFORNIA, SANTA BARBARA

MONTANA STATE UNIVERSITY

UNIVERSITY OF NEVADA

OREGON STATE COLLEGE

UNIVERSITY OF OREGON

UNIVERSITY OF SOUTHERN CALIFORNIA

\author{
STANFORD RESEARCH INSTITUTE \\ STANFORD UNIVERSITY \\ UNIVERSITY OF UTAH \\ WASHINGTON STATE COLLEGE \\ UNIVERSITY OF WASHINGTON
}

AMERICAN MATHEMATICAL SOCIETY

HUGHES AIRCRAFT COMPANY SHELL DEVELOPMENT COMPANY

Mathematical papers intended for publication in the Pacific Journal of Mathematics should be typewritten (double spaced), and the author should keep a complete copy. Manuscripts may be sent to any of the editors. Manuscripts intended for the outgoing editors should be sent to their successors. All other communications to the editors should be addressed to the managing editor, Alfred Horn at the University of California Los Angeles 24, California.

50 reprints of each article are furnished free of charge; additional copies may be obtained at cost in multiples of 50 .

The Pacific Journal of Mathematics is published quarterly, in March, June, September, and December. The price per volume (4 numbers) is $\$ 12.00$; single issues, $\$ 3.50$; back numbers (Volumes $1,2,3)$ are available at $\$ 2.50$ per copy. Special price to individual faculty members of supporting institutions and to individual members of the American Mathematical Society: $\$ 4.00$ per volume; single issues, $\$ 1.25$.

Subscriptions, orders for back numbers, and changes of address should be sent to the publishers, University of California Press, Berkeley 4, California.

Printed at Kokusai Bunken Insatsusha (International Academic Printing Co., Ltd.) No. 10 1-chome Fujimi-cho, Chiyoda-ku, Tokyo, Japan.

* During the absence of E. G. Straus. 


\section{Pacific Journal of Mathematics}

\section{Vol. 5, No. $5 \quad$ BadMonth, 1955}

Henry A. Antosiewicz, A theorem on alternatives for pairs of matrice . . . . . 641

F. V. Atkinson, On second-order non-linear oscillation ............... 643

Frank Herbert Brownell, III, Fourier analysis and differentiation over real separable Hilbert spac .................................. 649

Richard Eliot Chamberlin, Remark on the averages of real function ...... 663

Philip J. Davis, On a problem in the theory of mechanical quadrature ... . . 669

Douglas Derry, On closed differentiable curves of order $n$ in $n$-spac ...... 675

Edwin E. Floyd, Boolean algebras with pathological order topologie ... . . 687

George E. Forsythe, Asymptotic lower bounds for the fundamental frequency of convex membrane ................................. 691

Israel Halperin, On the Darboux propert ................... 703

Theodore Edward Harris, On chains of infinite orde .............. 707

Peter K. Henrici, On certain series expansions involving Whittaker functions

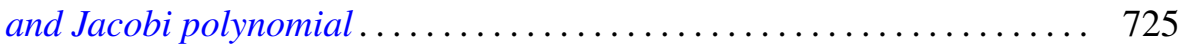

John G. Herriot, The solution of Cauchy's problem for a third-order linear hyperoblic differential equation by means of Riesz integral ......... 745

Jack Indritz, Applications of the Rayleigh Ritz method to variational

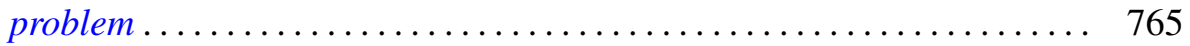

E. E. Jones, The flexure of a non-uniform bea ................. 799

Hukukane Nikaidô and Kazuo Isoda, Note on non-cooperative convex game.

Raymond Moos Redheffer and W. Wasow, On the convergence of asymptotic solutions of linear differential equation . . .

S. E. Warschawski, On a theorem of L. Lichtenstei ...........

Philip Wolfe, The strict determinateness of certain infinite game... 